\title{
Model for predicting academic performance in virtual courses through supervised learning
}

\author{
Autores \\ Jesús Silva, Evereldys Garcia Cervantes, Danelys Cabrera, Silvia García, María Alejandra Binda, \\ Omar Bonerge Pineda Lezama, Juan Lamby, Carlos Vargas Mercado
}

\begin{abstract}
Since virtual courses are asynchronous and non-presential environments, the following of student tasks can be a hard work. Virtual Education and Learning Environments (VELE) often provide tools for this purpose (Zaharia et al. in Commun ACM 59(11):56-65, 2016, [1]]). In Moodle, some plugins take information about students' activities, providing statistics to the teacher. This information may not be accurate with respect to leadership ability or risk of abandonment. The use of artificial neural networks (ANNs) can help predict student behavior and draw conclusions at early stages of the learning process in a VELE. This paper proposes a plugin for Moodle that analyzes social metrics through graph theory. This article outlines the advantages of integrating an ANN into this development that complements the use of the graph to provide rich conclusions about student performance in a Moodle virtual course.
\end{abstract}

Palabras clave:

Virtual education environments, Supervised learning, Moodle, Neural networks 